\title{
Clinical Trial Risk in Chronic Obstructive Pulmonary Disease: The Effects of Drug Class and Inclusion Criteria
}

\author{
Jeffrey T.Y. Tam ${ }^{a}$ Jayson L. Parker ${ }^{a}$ b Demetri Anastasopulos ${ }^{a}$ Meyer S. Balter \\ anstitute for Management and Innovation, Master of Biotechnology Program, and ${ }^{\mathrm{b}}$ Department of Biology, \\ University of Toronto Mississauga, Mississauga, Ont., and ${ }^{\mathrm{C}}$ Department of Medicine, University of Toronto, \\ Toronto, Ont., Canada
}

\section{Key Words}

Chronic obstructive pulmonary disease $\cdot$ Clinical trials .

Bronchodilators · Drug development

\begin{abstract}
Background: This study analyzed the risk of clinical trial failure in chronic obstructive pulmonary disease (COPD) drug development between 1998 and 2015. We investigated elements that influenced clinical trial risk and factors that could improve outcomes during development. Objectives: This study aims to quantify clinical trial risk for drug development in COPD and factors that affect clinical trial risk. Methods: Drugs that commenced their phase I testing in this indication from 1998 onwards were retrieved from http://www. clinicaltrials.gov. Compounds investigated had to have an endpoint relevant to the treatment of COPD and be sponsored by the pharmaceutical industry. These compounds were then analyzed based on their mechanism of action and trial inclusion criteria. Results: A total of 766 trials met our screening criteria representing 116 drugs. Of these, 9 gained approval by the US FDA during our study period. The cumulative success rate for clinical development in COPD was 13.4\%.Combination therapies of long-acting $\beta$-adrenoceptor agonists (LABA)/long-acting muscarinic antagonists (LAMA)
\end{abstract}

and inhaled corticosteroids (ICS)/LABA had the highest success rates at 80 and $50 \%$, respectively. The risk-adjusted cost for drug development in COPD was USD 532.4 million. Conclusions: A $13.4 \%$ success rate in COPD implies that less than 1 in 7 compounds enrolled into clinical testing would gain FDA approval. LABA/LAMA and ICS/LABA therapies had multiple fold increases in the success rate compared to other drug classes and sizably decreased the risk-adjusted cost of drug development. Moving forward, combination therapies may offer the lowest risk of clinical failure in COPD drug development.

(c) 2015 S. Karger AG, Basel

\section{Introduction}

Chronic obstructive pulmonary disease (COPD) has long been a leading cause of morbidity, mortality, and financial burden, with a cost of USD 38.8 billion annually in the US alone [1-3]. Recent estimates from the World Health Organization's Global Burden of Disease and Risk Factors project also showed that COPD was the fifth leading cause of death in high-income countries for 2001 [4]. As a result, there has been a strong interest in the use of pharmacologic interventions to improve health outcomes

\section{KARGER}

E-Mail karger@karger.com

www.karger.com/res (c) 2015 S. Karger AG, Basel

0025-7931/15/0911-0079\$39.50/0
Dr. Jayson L. Parker

Department of Biology, University of Toronto Mississauga

3359 Mississauga Road North, Room DV2071

Mississauga, ON L5L 1C6 (Canada)

E-Mail jayson.parker@ utoronto.ca 
in this disease [1]. Despite this, it still takes 13.5 years on average in the US to bring a new drug to market [5]. Furthermore, the pharmaceutical industry is suffering from a combination of decline in R\&D (research and development) productivity, lack of new approvals by the US FDA, and patent expiries [5]. This has caused the industry to place an increasing importance on risk mitigation during clinical development [6].

Clinical trials are commonly discussed in phases, with each phase designed to answer certain questions about a drug. Phase I tests a new drug in a small group of healthy individuals to evaluate safety and identify side effects. Phase II involves larger patient groups to evaluate effectiveness and safety, while phase III utilizes large patient groups to confirm efficacy, compare alongside common treatments, and monitor safety [7]. In this retrospective observational study, we quantified clinical trial risk - the risk of a drug failing during clinical testing - in COPD and compared it against industry-wide estimates for drug development [8]. Further, we examined factors that impact clinical trial risk in COPD using methodologies previously applied in other disease areas [9-15]. Understanding clinical trial risk has important implications for physicians who participate in COPD clinical trials to advance therapeutic development in this indication. In addition, this study may suggest specific clinical study designs in COPD that should receive priority for participation. Lastly, this research is also relevant to public policy decisions involving health care funding and support for drug research.

\section{Materials and Methods}

This study employs a similar methodology to previous clinical trial risk analysis research in HIV-1, Crohn's disease, breast cancer, non-Hodgkin's lymphoma, prostate cancer, rheumatoid arthritis, and non-small-cell lung cancer where comparable methodologies have been described [9-15]. Ethics approval was not applicable as this was a retrospective observational study on drug candidates without involving any patients.

\section{Study Eligibility and Patient Population}

Phase I, II, and III clinical trials for the treatment of COPD taking place between January 1, 1998 and July 1, 2015 were analyzed. To be eligible, compounds had to have started their phase I trial after January 1, 1998, have a clinical trial endpoint relevant to the treatment of COPD, and be sponsored by the pharmaceutical industry. With the exception of phase I studies, compounds were excluded if their respective studies were not registered on clinicaltrials.gov. Novel compounds were classified as having a unique molecular structure (confirmed through PubMed) as opposed to being reformulations. Combination therapies were also considered novel if neither compound in the combination had prior FDA approval for COPD.

\section{Database and Online Tools}

The online database clinicaltrials.gov was used as the primary source for data. With the advanced search function 'Interventions: drug', the following search terms were applied: COPD + clinical trial + phase I; COPD + clinical trial + phase II; COPD + clinical trial + phase III. Supplemental online database tools also included: PubMed, DrugBank.ca, Factiva (accessed through the University of Toronto Libraries), Business Wire (ProQuest 5000, accessed through the University of Toronto Libraries), and the US National Library of Medicine. To validate the information obtained, press releases, conference proceedings, and other publications were also analyzed.

Classes of medications for compounds studied were later divided into 5 categories, using the manufacturers' prescribing information, and verified through the resources listed above, along with the 2014 Global Initiative for Chronic Obstructive Lung Disease (GOLD) review: phosphodiesterase type 4 inhibitors, longacting $\beta$-adrenoceptor agonists (LABA), long-acting muscarinic antagonists (LAMA), LABA/LAMA, and inhaled corticosteroids (ICS)/LABA.

\section{Classifying Clinical Success and Failures}

A compound that advanced from phase I to phase II or from phase II to phase III was classified as a success. Phase III testing was only successful if the compound received FDA approval and has remained on the market. Additionally, phase I/II trials were classified as phase I and phase II/III trials were classified as phase II for analysis. Follow-up was completed by July 1, 2015. The clinical trial success rate and cumulative success rate were calculated as per the following equations:

$$
\begin{aligned}
& \text { Success rate for phase } X= \\
& \frac{(\text { number of drug candidates that moved onto phase } X+1)}{(\text { total number of drugs that participated in phase } X)} .
\end{aligned}
$$

\section{Cumulative success rate $=$}

(phase I success rate $) \times($ phase II success rate $) \times($ phase III success rate $)$.

Clinical trial failures were divided into two components: clinical failures and commercial failures. Clinical failures occurred when a drug failed to meet its primary endpoint (in phase II or III) or had significant safety issues during any phase of testing. Commercial failures were assigned to drugs that had successfully completed clinical testing, but showed no signs of further development for 2 years or more. Commercial failures could imply that the manufacturers decided to focus their investments on alternate clinical candidates with higher returns, or encountered financing hurdles during development. Drugs that had completed their trials but remained inactive for less than 2 years were classified as undetermined.

\section{Calculating Drug Development Costs}

Phase I, II, and III studies performed by the drug's manufacturer from January 1, 1998 until the date of FDA approval were located using clinicaltrials.gov. Supplemental data were also requested from the manufacturer's Medical Information Department. Cost estimates for each phase of testing were calculated by averaging the number of patients enrolled in each trial per phase and multiplying it by the average per patient cost of clinical testing 


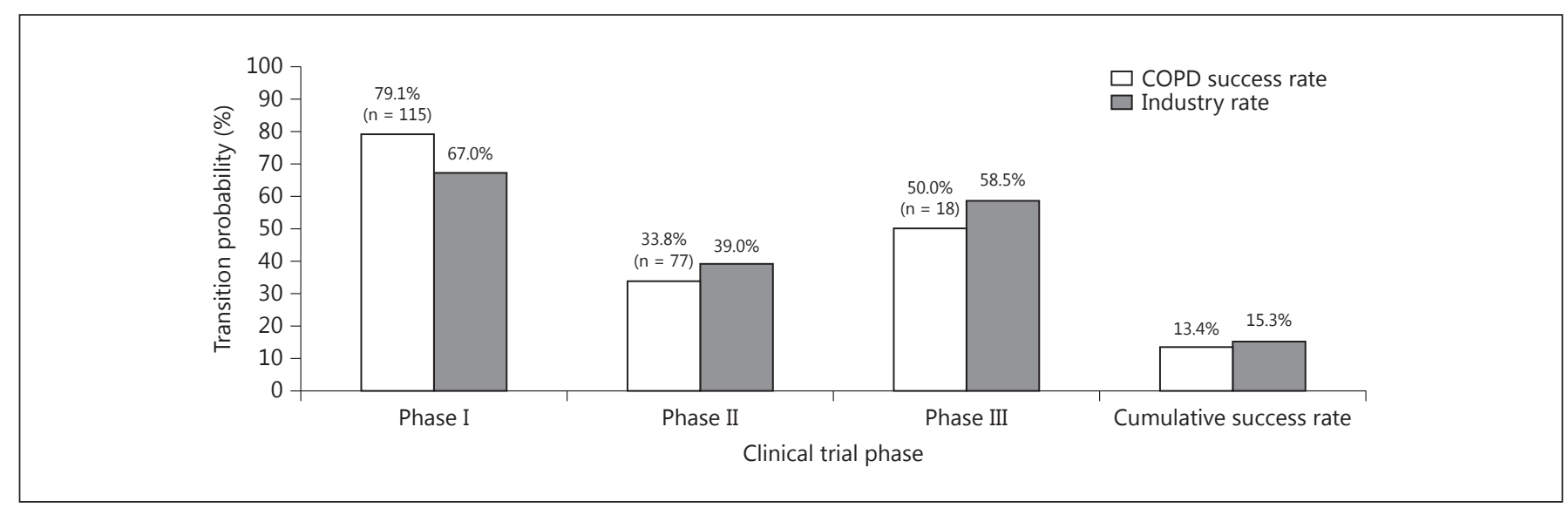

Fig. 1. Clinical trial success rates in COPD are displayed along with industry-wide rates. Drugs that entered phase I clinical testing during or after January 1998 were tracked up until July 2015. Clinical trial success rate refers to the probability of a drug ad- vancing from the current phase of clinical study to the next phase or from phase III to FDA approval. Cumulative success rates represent the product of clinical trial success rates for each phase.
[16]. The total cost per phase, with respect to the number of trials required, and the cost per trial are referred to as the 'unadjusted development cost'. In the clinical trial, we then factored success rates along with a $9 \%$ yearly discount rate to calculate the 'riskadjusted cost' [17].

\section{Results}

Our initial search yielded 2,284 hits from https:// clinicaltrials.gov. Of these, 766 studies met our criteria of taking place between January 1998 and July 2015 with an endpoint relevant to COPD, being sponsored by the industry, and with registration on clinicaltrials. gov. Overall, this represented a total of 116 drugs with 9 new US drug approvals for the indication. These included inhalations of indacaterol [18], fluticasone furoate and vilanterol [19], fluticasone propionate and salmeterol [20], umeclidinium and vilanterol [21], umeclidinium [22], budesonide and formoterol fumarate dehydrate [23], aclidinium bromide [24], roflumilast [25], and olodaterol [26].

\section{Clinical Success Rate in COPD}

Figure 1 illustrates the clinical trial success rates for COPD across each phase of testing and contrasts this against industry rates. The cumulative success rate of $13.4 \%$ in COPD is slightly lower than the industry aggregate rate of $15.3 \%$ [8]. Phase I was the only phase of testing where COPD compounds showed a higher success rate of
$79.1 \%$ compared to industry standards at $67 \%$. In both phase II and III studies, COPD success rates showed a drop to 33.8 and 50\%, respectively, and were lower than industry rates [8].

Due to the tendency for different types of medication to be prescribed in COPD [27-29], it was hypothesized that overall success rates may not have been an accurate representation of success rates across all the drug classes undergoing clinical trials. Thus, figure 2 compares success rates for compounds tested in drug classes currently approved for COPD. Cumulative success rates were perceivably heterogeneous across drug mechanisms ranging from $11 \%$ with LABA to $80 \%$ with LABA/LAMA combinations. In particular though, LABA/LAMA and ICS/ LABA combination therapies displayed especially high success rates of 80 and $50 \%$, respectively.

\section{Clinical Failures and Inclusion Criteria}

In figure 3, we examined the reasons behind clinical trial failures. Commercial failures made up the majority of drug failures across all phases of clinical development. If we exclude commercial failures from our dataset and only considered clinical failures as a true measure of clinical trial risk, success rates in COPD then become $96.8 \%$ for phase I, $68.4 \%$ for phase II, and $81.8 \%$ for phase III. This gives a cumulative success rate of $54.2 \%$, more than a fourfold increase from our original of $13.4 \%$.

Looking into the patient inclusion criteria for clinical studies in our next step, we compared two common inclusion criteria in figure 4: smoking years and GOLD 


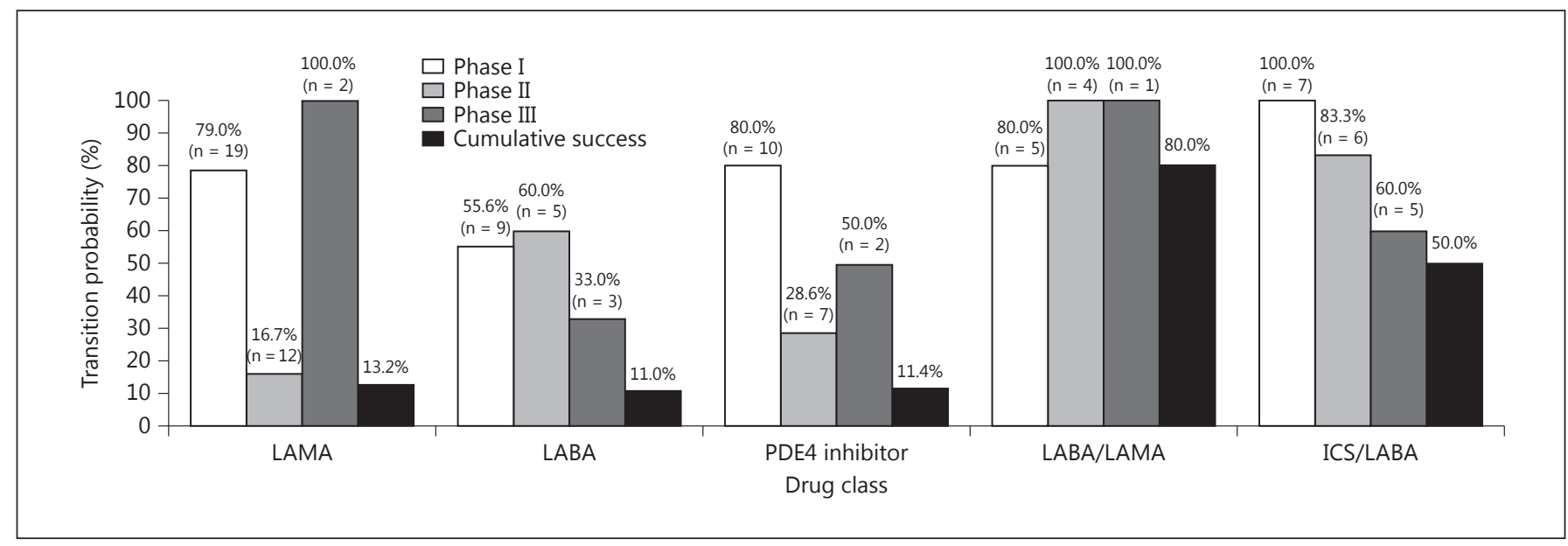

Fig. 2. Clinical trial success rates for COPD drug candidates by drug class are displayed alongside industry-wide success rates. This figure displays parallel analyses for success rates of COPD compounds across various drug classes. Clinical trial success rate refers to the probability of a drug advancing from the current phase of clinical study to the next phase or from phase III to FDA approval. Cumulative success rates represent the product of clinical trial success rates for each phase. PDE4 $=$ Phosphodiesterase type 4 .
Fig. 3. Clinical trial failure causes in COPD. Clinical trial failure was classified either as clinical or commercial. Clinical failures were designated when drugs failed to meet primary endpoints (in phases II or III) or had significant safety issues during any phase of clinical testing. Drugs were designated as commercial failures when they successfully completed clinical testing but failed to show signs of further development for 2 years or more. Those that had been inactive for less than 2 years were classified as undetermined.

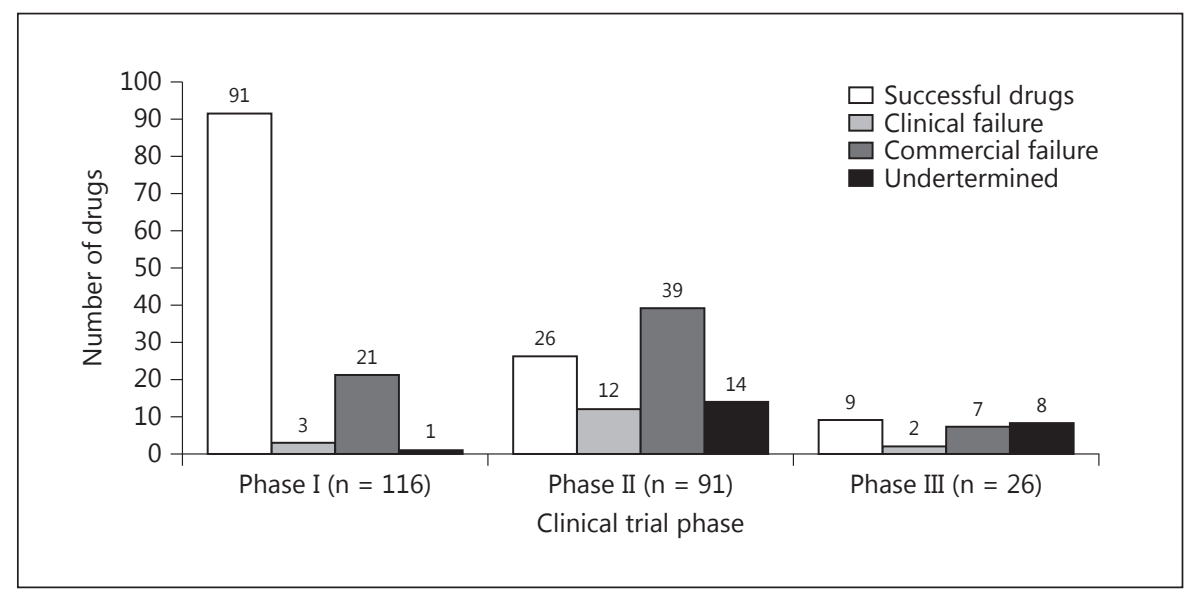

staging [28]. Studies that specified patients to a smoking history of over 10 years had an $18.8 \%$ success rate compared to $12.5 \%$ in those that did not. Also, studies utilizing GOLD staging in their inclusion criteria demonstrated a $22.2 \%$ success rate when patients included were GOLD 3 or 4, compared to $0 \%$ success in studies only involving GOLD 1 or 2 patients.

\section{Drug Development Costs}

Figure 5 illustrates the unadjusted and risk-adjusted development costs for drugs in COPD. The cost per trial per phase of clinical testing was calculated (in USD) to be: 2.4 million for a phase I trial, 12.4 million for a phase II trial, and 32.6 million for a phase III trial. We also calculated the average number of trials a COPD drug would go through at each stage of clinical testing and their average duration: 3 phase I trials at 0.7 years, 2 phase II trials at 1 year, and 8 phase III trials at 1.2 years. Based on this, the unadjusted development cost of a COPD drug was USD 292.8 million. When accounting for the success rates in this indication, the risk-adjusted drug development cost rose markedly from USD 292.8 million to USD 532.4 million. Finally, having shown the highest success rates in LABA/LAMA and ICS/LABA combination therapies (fig. 2), we calculated risk-adjusted drug development costs specific to success rates for each of these drug class- 


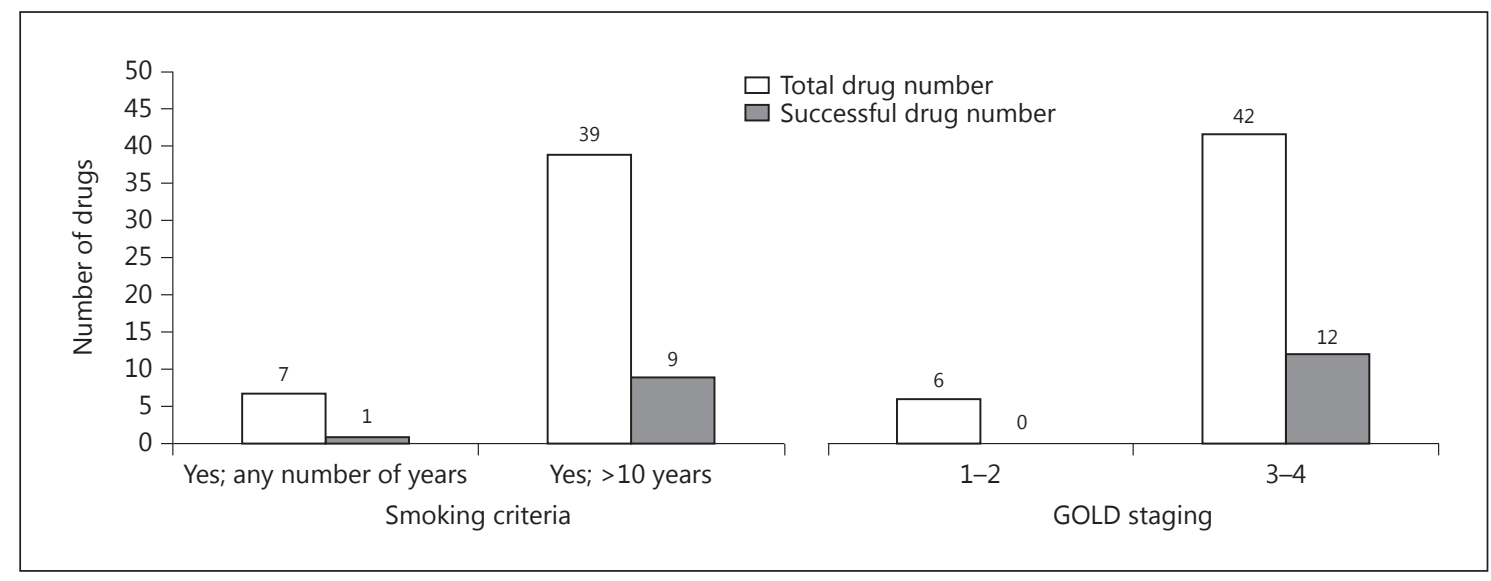

Fig. 4. Clinical trial success in COPD segmented by the patient inclusion criteria is displayed. We chose to analyze the impact from two of the most common inclusion criteria: smoking years and GOLD staging. The number above each bar represents the number of drug programs utilizing the particular inclusion criteria for their patient selection process.

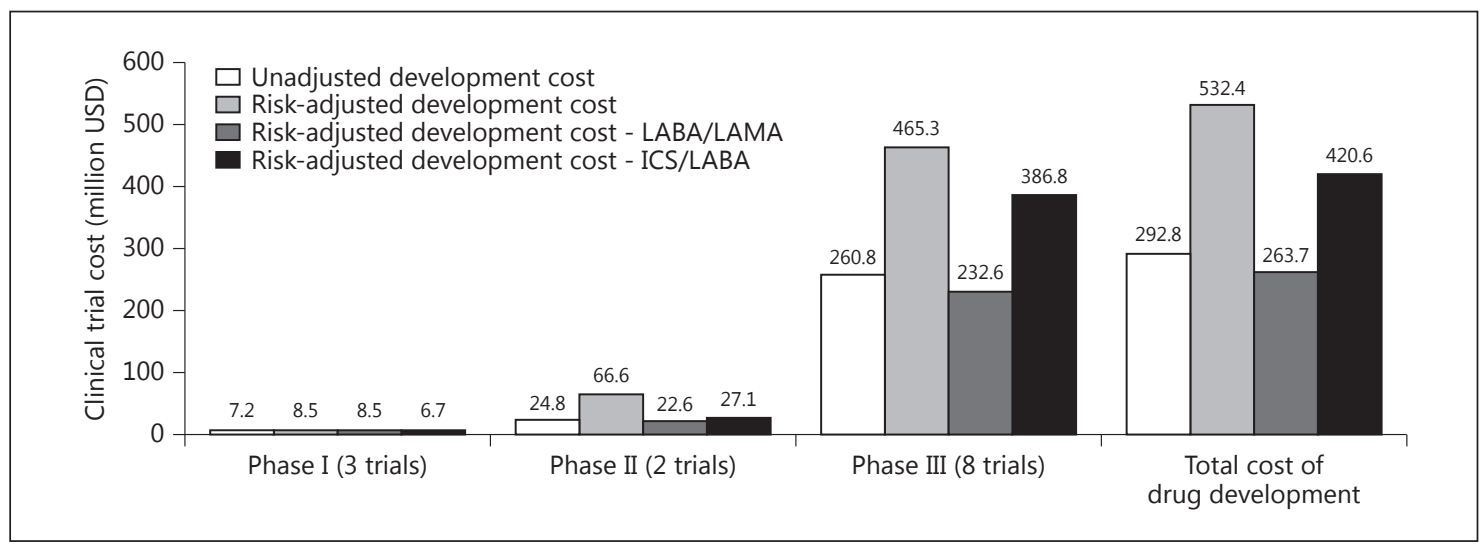

Fig. 5. The estimated clinical trial costs for drug development in COPD. The unadjusted cost was the product of the number of trials and cost per trial. The risk-adjusted cost was calculated applying success rates of each particular drug mechanism along with a $9 \%$ yearly discount rate to estimate present day currency. The number above each bar represents the cost in millions of USD.

es. Risk-adjusted costs for LABA/LAMA and ICS/LABA therapies were USD 263.7 million and USD 420.6 million, respectively, i.e. a substantial drop from our original of USD 532.4 million.

\section{Discussion}

This study quantified clinical trial risk in COPD and identified factors that impacted this estimate in trials taking place between January 1998 and July 2015. We found that studies including patients with more advanced stages of COPD such as GOLD 3 and 4 patients showed higher success rates at $22.2 \%$ in relation to $0 \%$ in those that only recruited GOLD 1 or 2 patients. Overall, this indication had a lower cumulative success rate at $13.4 \% \mathrm{com}$ pared to aggregate industry standards [8] although combination therapies had much higher cumulative success rates with LABA/LAMA therapies at $80 \%$ and ICS/LABA therapies at $50 \%$. The risk-adjusted cost for clinical development in COPD was USD 532.4 million. This figure dropped to USD 263.7 million or USD 420.6 million with 
drug candidates that were LABA/LAMA or ICS/LABA combination therapies, respectively. Collectively, our study suggests that the success rate of clinical trials in COPD could be improved, based on patient recruitment criteria and class of medication being studied.

Studies utilizing inclusion criteria that selected for patients in a more advanced stage of the disease performed better than those that did not. This was seen in figure 4 where phase II study data - the phase of clinical testing with the highest failure rate - compared inclusion criteria with respect to smoking years and GOLD staging. The contrast between success rates in studies involving GOLD 3 or 4 patients compared to those using GOLD 1 or 2 patients (fig. 4) is worth further discussion and speculation, possibly in another publication specifically focusing on patient inclusion and exclusion criteria.

Overall, the $13.4 \%$ success rate of compounds going through clinical development in COPD indicates that less than 1 in every 7 drug candidates entering clinical development would emerge successful with FDA approval. Particularly, this indication had low phase II and phase III success rates (fig. 1), suggesting noticeable challenges to drug advancement in these phases, at least compared to success rates in other disease indications such as HIV1 or Crohn's disease $[9,10]$. However, LABA/LAMA and ICS/LABA combination therapies show promise with the highest success rates compared to other drug classes (fig. 2). The additive effects of combination therapies have previously been suggested in the literature to provide greater benefit and are recommended by multiple treatment guidelines for patients showing a lack of response to monotherapy or entering advanced stages of the disease [27-30]. In this paper, our results present a stark contrast between the success rate of novel LABA monotherapies at $11 \%$, compared to LABA/LAMA or ICS/LABA combination therapies at 80 and 50\%, respectively.

Our calculations on the risk-adjusted development cost for drugs undergoing clinical testing in COPD was determined to be USD 532.4 million. This is higher than the costs previously reported from similar research in breast cancer (USD 274 million) [11] but still sizably lower than those in prostate cancer (USD 1.41 billion) [13] and non-small-cell lung cancer (USD 1.89 billion) [15]. The risk-adjusted cost showed a marked drop to USD 263.7 million and USD 420.6 million for LABA/LAMA and ICS/LABA combination therapy programs, respectively. This was largely due to the higher cumulative success rates shown in combination therapies compared to the indication as a whole (fig. 1).
Prima facie, these results would support the pursuit of combination therapies in the advancement of medications through clinical testing in COPD. However, although this minimizes the risk of clinical failure and losing financial investments from a clinical trial risk perspective, the launch of these 'me too' products based on well-known mechanisms may in turn encounter significant commercial challenges in the marketplace. Overall, COPD has traditionally been an area where manufacturers have looked to improve on drugs with well-known mechanisms of action and where new therapies may only be slight improvements over their predecessors [31,32]. Thus, products not first to market in their respective drug classes may encounter significant commercial hurdles in differentiating from competitors or changing clinical practice in an already crowded marketplace. Therefore, better commercial and patient outcomes may be obtained with alternative drug classes albeit at the expense of increased clinical risk. Recently, a phase III trial was initiated studying the use of a new triple combination therapy (LABA/LAMA/ICS) for reducing exacerbations in COPD patients [33]. Furthermore, drug developers are also investigating the use of biologic medications with similar exacerbation-related endpoints in mind for this indication [34, 35]. Moving forward in this indication, it would be interesting to see if physicians and manufacturers show emphasis on combination therapies for reduced clinical trial risk, or on more novel drug classes that may produce better commercial and patient outcomes.

This study has several limitations, most of which have been discussed in research employing similar methodologies [9-15]. Examining specific disease indications can result in smaller sample sizes of compounds for analysis, and compounds that have since been approved after the study period may thus affect results. This issue is also affected as compounds may be approved across different timelines with regulatory bodies outside of the FDA. This analysis may also overestimate the incidences of commercial failure, as situations where clinical issues were not disclosed would have been classified as a commercial failure. In addition, the equally weighting phases I, II, and III of clinical development for calculating cumulative success rates may not be perfectly representative of actual drug development nor the difficulties associated with successfully completing each phase. As such, we do not see our results as definitive, but as an illustration of possible trends for future investigations. 


\section{Conclusion}

The cumulative success rate of new drug development during clinical testing in COPD was $13.4 \%$, which is lower than the aggregate industry standards [8]. LABA/ LAMA and ICS/LABA combination therapies resulted in multiple fold increases in the overall success rate and also appreciably decreased the risk-adjusted cost of drug development. Our analysis puts forward the idea that combination therapies offer the lowest probability of clinical risk during drug development in COPD.

\section{Financial Disclosure and Conflicts of Interest}

Jeffrey Tam is currently a Territory Associate at GlaxoSmithKline Canada. Dr. Balter serves on the speaker's bureau for Almirall; AstraZeneca; Boehringer Ingelheim; Merck, Novartis, and Takeda, and has served on the scientific advisory board for Almirall; AstraZeneca; Boehringer Ingelheim; GlaxoSmithKline, and Novartis. Dr. Parker has worked in the pharmaceutical industry and is an advisor to a hedge fund, which may or may not have investments pertaining to any products mentioned in this study. Demetri Anastasopulos has reported no conflicts of interest.

\section{References}

$\checkmark 1$ Sullivan SD, Ramsey SD, Lee TA: The economic burden of COPD. Chest 2000;117:5S9S.

-2 Halbert RJ, Natoli JL, Gano A, Badamgarav E, Buist AS, Mannino DM: Global burden of COPD: systematic review and meta-analysis. Eur Respir J 2006;28:523-532.

-3 Foster TS, Miller JD, Marton JP, Caloyeras JP, Russell MW, Menzin J: Assessment of the economic burden of COPD in the US: a review and synthesis of the literature. COPD 2006;3:211-218.

4 Lopez AD, Mathers CD, Ezzati M, Jamison DT, Murray CJL: Global Burden of Disease and Risk Factors. Washington, The World Bank, 2006.

5 Paul SM, Mytelka DS, Dunwiddie CT, et al: How to improve R\&D productivity: the pharmaceutical industry's grand challenge. Nat Rev Drug Discov 2010;9:203-214.

6 Honig P, Lalonde R: The economics of drug development: a grim reality and a role for clinical pharmacology. Clin Pharmacol Ther 2010;87:247-251.

7 US National Library of Medicine: Clinical trial phases. 2008. http://www.nlm.nih.gov/services/ctphases.html (accessed August 7, 2015).

8 Hay M, Thomas DW, Craighead JL, Economides C, Rosenthal J: Clinical development success rates for investigational drugs. Nat Biotechnol 2014;32:40-51.

-9 Osborne BJW, Kaul R, Parker JL: Drug development risk in HIV-1 clinical trials: the effect of drug class. J Pharm Health Serv Res 2011;2: 211-216.

10 Parker JL, Clare Kohler J: The success rate of new drug development in clinical trials: Crohn's disease. J Pharm Pharm Sci 2010;13: 191-197.

11 Parker JL, Lushina N, Bal PS, Petrella T, Dent R, Lopes G: Impact of biomarkers on clinical trial risk in breast cancer. Breast Cancer Res Treat 2012;136:179-185.
12 Parker JL, Zhang ZY, Buckstein R: Clinical trial risk in Non-Hodgkin's lymphoma: endpoint and target selection. J Pharm Pharm Sci 2011;14:227-235.

13 Tenuta A, Klotz L, Parker JL: Clinical trial risk in castration resistant prostate cancer: immunotherapies show promise. BJU Int 2014; 113:E82-E89.

14 Jayasundara KS, Keystone EC, Parker JL: Risk of failure of a clinical drug trial in patients with moderate to severe rheumatoid arthritis. J Rheumatol 2012;39:2066-2070.

15 Falconi A, Lopes G, Parker JL: Biomarkers and receptor targeted therapies reduce clinical trial risk in non-small-cell lung cancer. J Thorac Oncol 2014;9:163-169.

16 Cutting Edge Information: Clinical development and trial operations: protocol design and cost per patient benchmarks. 2013. http:// www.cuttingedgeinfo.com/research/clinicaldevelopment/trial-operations/ (accessed February 15,2014 )

17 Harrington SE: Cost of capital for pharmaceutical, biotechnology, and medical devices firms; in Danzon PM, Nicholson S (eds): The Oxford Handbook of the Economics of the Biopharmaceutical Industry. Oxford, Oxford University Press, 2012.

18 US Food and Drug Administration: FDA approves Arcapta Neohaler to treat chronic obstructive pulmonary disease. 2011. http:// www.fda.gov/NewsEvents/Newsroom/Press Announcements/ucm261649.htm (accessed March 8, 2014).

19 US Food and Drug Administration: FDA approves Breo Ellipta to treat chronic obstructive pulmonary disease. 2013. http://www.fda. gov/newsevents/newsroom/pressannouncements/ucm351664.htm (accessed March 8, 2014).
20 GlaxoSmithKline: FDA approves ADVAIR 250/50 for reduction of exacerbations in patients with COPD. 2014. http://us.gsk.com/ $\mathrm{html} /$ media-news/pressreleases/2008/2008_ us_pressrelease_10040.htm (accessed March $8,2014)$.

21 US Food and Drug Administration: FDA approves Anoro Ellipta to treat chronic obstructive pulmonary disease. 2013. http://www.fda. gov/newsevents/newsroom/pressannouncements/ucm379057.htm (accessed March 8, 2014).

22 GlaxoSmithKline: GSK receives approval for Incruse $^{\mathrm{TM}}$ Ellipta $^{\circledR}$ (umeclidinium) in the US for the treatment of COPD\&nbsp. 2014. http://us.gsk.com/en-us/media/press-releases/2014/gsk-receives-approval-for-incruseellipta-umeclidinium-in-the-us-for-thetreatment-of-copdandnbsp/ (accessed May 1, 2014).

23 AstraZeneca: FDA approves Symbicort for chronic obstructive pulmonary disease. 2009. http://www.astrazeneca.com/Media/Pressreleases/Article/20090302-FDA-ApprovesSymbicort-for-Chronic-Obstructive-Pulmon (accessed March 9, 2014).

24 US Food and Drug Administration: FDA approves Tudorza Pressair to treat chronic obstructive pulmonary disease. 2012. http:// www.fda.gov/NewsEvents/Newsroom/PressAnnouncements/ucm313052.htm (accessed March 9, 2014).

25 US Food and Drug Administration: FDA approves new drug to treat chronic obstructive pulmonary disease. 2011. http://www. fda.gov/NewsEvents/newsroom/Press Announcements/ucm244989.htm (accessed March 9, 2014).

26 US Food and Drug Administration: FDA approves Striverdi Respimat to treat chronic obstructive pulmonary disease. 2014. http:// www.fda.gov/NewsEvents/Newsroom/Press Announcements/ucm407465.htm (accessed July 30,2015$)$. 
27 O’Donnell DE, Hernandez P, Kaplan A, Aaron S, Bourbeau J, Marciniuk D, Balter M, Ford G, Gervais A, Lacasse Y, Maltais F, Road J, Rocker G, Sin D, Sinuff T, Voduc N: Canadian Thoracic Society recommendations for management of chronic obstructive pulmonary disease - 2008 update - highlights for primary care. Can Respir J 2008;15(suppl A): $1 \mathrm{~A}-8 \mathrm{~A}$.

28 GOLD: Global strategy for the diagnosis, management, and prevention of chronic obstructive pulmonary disease. 2014. http:// www.goldcopd.org/uploads/users/files/ GOLD_Report2014_Feb07.pdf (accessed March 9, 2014).

29 NICE: Chronic obstructive pulmonary disease: management of chronic obstructive pulmonary disease in adults in primary and sec- ondary care (partial update). 2010. http:// www.nice.org.uk/guidance/cg101 (accessed March 9, 2014).

30 In chronic obstructive pulmonary disease, a combination of ipratropium and albuterol is more effective than either agent alone. An 85day multicenter trial. COMBIVENT Inhalation Aerosol Study Group. Chest 1994;105: 1411-1419.

31 Wanted: new treatments for COPD. Lancet Respir Med 2014;2:434-436.

32 Cazzola M, Page C: Long-acting bronchodilators in COPD: where are we now and where are we going? Breathe 2014;10:110-120.

33 GlaxosmithKline: GSK and Theravance announce initiation of phase III programme with fixed dose triple combination treatment FF/UMEC/VI in patients with COPD. 2014. http://www.gsk.com/media/press-releases/2014/gsk-and-theravance-announce-initiation-of-phase-iii-programme-wi.html (accessed August 3, 2014).

34 GlaxoSmithKline: GSK announces start of phase III programme for mepolizumab in patients with COPD. 2014. http://www.gsk. com/en-gb/media/press-releases/2014/gskannounces-start-of-phase-iii-programmefor-mepolizumab-in-patients-with-copd/ (accessed August 3, 2014).

35 AstraZeneca: AstraZeneca to present respiratory data at ATS 2014 international conference. 2014. http://www.astrazeneca.com/Media/Press-releases/Article/20140512-AstraZeneca-to-present-respiratory-data-ATS2014-International-Conference (accessed August 3, 2014). 